OTOLOGY

\title{
Bone-anchored hearing implant surgery: our experience with linear incision and punch techniques
}

\author{
La chirurgia delle protesi acustiche ancorate all'osso: \\ la nostra esperienza con le tecniche con incisione lineare e con punch \\ F. DI GIUSTINO, P. VANNUCCHI, R. PECCI, A. MENGUCCI, R. SANTIMONE, B. GIANNONI \\ Audiology Unit, AOU Careggi, Department of Surgery and Translational Medicine, University of Florence, Italy
}

\section{SUMMARY}

In recent years, bone-anchored hearing implants (BAHIs) have found wider application in the treatment of conductive and mixed hearing loss. Several surgical techniques have been developed to reduce complications, enhance healing and improve audiological and aesthetic results. We report our experience on the use of three BAHI surgery techniques: Group 1, linear incision with thinning of the subcutaneous tissue; Group 2, linear incision without thinning of the subcutaneous tissue; Group 3, punch technique (Minimally Invasive Ponto Surgery, MIPS). We retrospectively analysed patients undergoing BAHI surgery; results were evaluated on the basis of any intra-operative complication, duration of surgery and occurrence of adverse effects at the implantation site over 1 year of follow-up. We collected a total of 30 implantations (12 for Group 1, 8 for Group 2, 10 for Group 3) with an intra-operative complication rate of $25 \%, 0 \%$ and $10 \%$, respectively. The average surgical time was 62.08 minutes, 34.37 minutes and 18.7 minutes respectively. During follow-up, we reported the occurrence of adverse effects in $10.63 \%$ of observations in Group 1, 3.12\% in Group 2 and 2.5\% in Group 3. This study confirms the low rate of intra and postoperative complications during BAHI surgery and documents the simplicity of execution of the novel MIPS technique, with a significant reduction in surgical time compared to the other two techniques, and positive effects in terms of health care costs.

KEY WORDS: Bone-anchored hearing implants $\bullet$ Punch technique $\bullet$ Linear incision $\bullet$ Minimally Invasive Ponto Surgery

\section{RIASSUNTO}

Negli ultimi anni, le protesi acustiche ancorate all'osso (BAHIs) hanno trovato larga applicazione nel trattamento delle ipoacusie trasmissive e miste. Sono state sviluppate diverse tecniche chirurgiche per ridurre le complicanze, accelerare la guarigione, migliorare i risultati audiologici ed estetici. Nel presente studio riportiamo la nostra esperienza nell'uso di tre tecniche chirurgiche per l'impianto delle protesi acustiche ancorate all'osso: Gruppo 1, incisione lineare con assottigliamento del tessuto sottocutaneo; Gruppo 2, incisione lineare senza assottigliamento del tessuto sottocutaneo; Gruppo 3, tecnica a punch (Minimally Invasive Ponto Surgery, MIPS). I pazienti sottoposti a questo tipo di chirurgia sono stati studiati in via retrospettiva e i risultati valutati sulla base dell'eventuale comparsa di complicanze intraoperatorie, durata dell'intervento e comparsa di reazioni locali nel sito di impianto durante un follow-up di 1 anno. Abbiamo raccolto un totale di 30 impianti (12 per il Gruppo 1, 8 per il Gruppo 2, 10 per il Gruppo 3), con un tasso di complicanze intraoperatorie del 25\%, $0 \%$ e 10\% rispettivamente. La durata media dell'intervento è stata di 62,08 minuti, 34,37 minuti e 18,7 minuti rispettivamente. Durante il follow-up abbiamo osservato la comparsa di reazioni locali nel 10,63\% delle osservazioni nel Gruppo 1, 3,12\% nel Gruppo 2, 2,5\% nel Gruppo 3. Questo studio conferma il basso tasso di complicanze intra e postoperatorie nella chirurgia delle protesi acustiche ancorate all'osso e mostra la semplicità di esecuzione della nuova tecnica MIPS, con una riduzione significativa dei tempi chirurgici rispetto alle altre due tecniche utilizzate ed effetti positivi in termini di costi sanitari.

PAROLE CHIAVE: Protesi acustiche ancorate all'osso • Tecnica a punch • Incisione lineare • Minimally Invasive Ponto Surgery

Acta Otorhinolaryngol Ital 2018;38:257-263

\section{Introduction}

In recent years, hearing aids have seen a remarkable development in terms of sound quality and potential for application. In the treatment of conductive and mixed hearing loss, or single-sided deafness, bone-anchored hearing implants (BAHIs) have found wide application, overcoming some important disadvantages that may oc- 
cur with traditional bone conduction devices (BCDs). The latter, in fact, need good contact between the transducer and temporal bone through a high pressure on the skin, with the possibility of developing inflammation, pain and lesions. Their prolonged use is often associated with onset of headache. Another important disadvantage in this kind of device is due to the filtering effect on some frequencies by the interposed skin layer, with dissipation of a certain amount of energy and deterioration in the quality of sound. Furthermore, the correction of severe hearing losses requires the application of an important amount of sound energy, which results in distortion phenomena and further loss of quality. In addition, the aesthetic problem related to this kind of device, usually placed in the glasses temple tips, should not be overlooked ${ }^{1}$. Regarding this latter aspect, more comfortable BCDs have been developed in recent years, such as Bruckhoff hearing systems, that elegantly combine glasses with a hearing module inserted in malleable temple tips; the result is a small, discreet and comfortable system that allows considerable improvement in aesthetic appearance ${ }^{2}$. With reference to the other aspects, percutaneous implants outdo these difficulties through a titanium abutment surgically inserted in the temporal bone, which after osseo-integration allows bone transmission of sound from an external receiver directly to the inner ear, with an improvement of the auditory gain of at least 10-25 dB compared to conventional bone conduction devices ${ }^{3}$. However, the installation of such devices is not free of complications. In fact, the standard surgical technique described by Tjellström et al. in 1977, used for decades, requires the creation of a pedicle skin flap with extensive thinning of the subcutaneous tissue until the periosteum ${ }^{34}$; this can lead to the appearance of an area of alopecia around the device and can compromise revascularization of the skin flap with risk of dysesthesia, infections and impaired wound healing, with possible aesthetic implications ${ }^{5}$. Recently, to enhance healing and aesthetic results, less invasive techniques have been adopted that use a linear incision of the skin with thinning of the subcutaneous tissue ${ }^{67}$; the introduction of longer abutments has allowed to avoid the thinning of the subcutaneous tissue. This technique has many benefits: it shortens both surgical and healing time, brings no significant dysesthesia in long-term follow-up, and reduces local infections with a better appearance of the surgical area ${ }^{89}$. An additional evolution of the technique has further reduced surgical trauma through the use of a biopsy punch and removal of a piece of skin, subcutaneous tissue and periosteum through which the housing for the abutment in the temporal bone is achieved. This technique shortens surgical times, accelerates healing, improves aesthetic ap- pearance and reduces the risk of skin overgrowth around the abutment ${ }^{310}$.

In recent years, a non-skin-penetrating bone conduction hearing implant has also been developed that uses a magnetic coupling through the skin. A passive magnet is implanted under the soft tissue of the scalp and anchored to the skull; an external active sound processor is attached to a second magnet and positioned over the implanted anchor. The magnetic attraction allows to hold the processor in place and to transmit acoustic energy. The limits of this kind of device are represented by energy loss through the skin layer and possible discomfort and complications due to soft tissue pressure ${ }^{11}{ }^{12}$. Unfortunately, our experience with magnetic BAHIs is still insufficient for a definite conclusion.

In this paper, we report our experience on the use of three bone-anchored hearing implants surgery techniques: 1) linear incision with thinning of the subcutaneous tissue; 2) linear incision without thinning of the subcutaneous tissue; 3 ) punch technique (Minimally Invasive Ponto Surgery).

\section{Materials and methods}

This retrospective study was carried out on patients with middle/inner ear disorders causing conductive or mixed hearing loss who underwent application of a bone-anchored hearing implant. In all our patients, the decision to resort to this kind of solution was taken after an unsuccessful trial with conventional BCDs.

The results were evaluated on the basis of any intra-operative complication, duration of surgery and occurrence of adverse effects at the implantation site. The latter was assessed by applying Holgers classification (Table I) during 4 postoperative control visits (T1, 7 days; T2, 30 days; T3, 60 days; T4, 1 year). Patients were divided into 3 groups based on the used surgical technique and the implanted processor. Patients in Group 1 were implanted with a Baha ${ }^{\circledR}$ System (Cochlear Bone Anchored Solutions, Mölnlycke, Sweden) and those in Groups 2 and 3 with a Ponto ${ }^{\mathrm{TM}}$ System (Oticon Medical AB, Askim, Sweden). The allocation of patients in the three groups was determined by surgical technique

Table I. Holgers classification of skin reaction.

\begin{tabular}{ll}
\hline Grade 0 & No skin reaction \\
Grade 1 & Redness with slight swelling \\
Grade 2 & Redness, moistness and moderate swelling \\
Grade 3 & Redness, moistness and moderate swelling, with tissue granulation \\
Grade 4 & Profound signs of infection, resulting in removal of the implant \\
\hline
\end{tabular}


evolution over the years and the availability of newer hearing devices at our clinic.

All patients signed an informed consent form.

Data were collected and processed using the Epi Info ${ }^{\mathrm{TM}}$ 7.2.0.1 (CDC, USA).

\section{Group 1. Linear incision with thinning \\ of the subcutaneous tissue}

After performing a trichotomy on the surgical area, the site of implant was identified $65 \mathrm{~mm}$ posterior-superiorly from tragus. Under local anaesthesia (Mepivacaine $20 \mathrm{mg} / \mathrm{ml}$ with adrenaline 1:100.000), a linear vertical incision down to the periosteum was made; retractors were positioned, and a cross-cut was made on the periosteum, which was then centrifugally moved away from the site of the implant, where a $3 \mathrm{~mm}$ hole was practiced, then deepened to $4 \mathrm{~mm}$ and widened. Subsequently, the fixture with the abutment was inserted and the subcutaneous tissue adjacent to the cut was thinned. After suturing the incision with Vicryl, the healing cap was applied and gauze with antibiotic ointment was delicately wrapped beneath it to exert a slight pressure on the surgical cut. Finally, a compression dressing was applied.

\section{Group 2. Linear incision without thinning of the subcutaneous tissue}

The surgical procedure is analogous to that in Group 1, but differed in the need to measure skin thickness with a needle before infiltration of local anaesthetics (to use an abutment with the right length) and for the lack of thinning of the subcutaneous tissue.

\section{Group 3. Punch technique (MIPS)}

This technique was performed according to the new procedure developed by Oticon Medical AB, Askim, Sweden (MIPS) for the application of their implants. After trichotomy, the site of implantation is determined by the intersection of two lines, the first starting from the external corner of the homolateral eye and going posteriorly tangentially to the helix and the other starting from the external auditory meatus and going posterior-superiorly for $55-65 \mathrm{~mm}$. The skin thickness was measured before the infiltration of local anaesthetics as for Group 2. A circular incision up to the bone surface was then practiced with a $5 \mathrm{~mm}$ diameter biopsy punch. Through the incision, the periosteum was carefully removed from the implant site using a raspatorium and after positioning a guide cannula, a guide drill was first used with a spacer in place to realise a guide hole of $3 \mathrm{~mm}$. Once confirmed the presence of bone at the implant site with a probe, the spacer was removed and the guide hole deepened to
$4 \mathrm{~mm}$. Next, a widening drill was used to widen the hole. Prior to all steps, the cannula was filled with saline solution and copious irrigation was used during and after drilling to facilitate cooling and removal of bone debris. Inserted the abutment through the incision, the healing cap, the gauze with antibiotic ointment and an external dressing were applied.

\section{Results}

We collected data on 29 patients with a mean age 60.41 years (range 24-87), 16 of which were women $(55.17 \%$ ) and 13 men $(44.83 \%)$. We performed bilateral implantation on one patient, for a total of 30 recorded implants, 14 to the right $(46.7 \%)$ and 16 to the left $(53.3 \%)$. All surgeries were performed by the same experienced surgeon (PV) except for 2 cases in Group 3, which were performed by a young surgeon (RP).

In Table II we report the adverse effects of the three groups during follow-up, as assessed by Holgers classification.

\section{Group 1}

This technique was used in 12 cases (40\%). During surgery, there were no complications in 9 cases $(75 \%)$; in 1 case $(8.33 \%)$, while drilling, the Dura Mater was exposed with important bleeding thus requiring the displacement of the site of implant; in 2 cases (16.67\%), while drilling the hole, there was temporary bone bleeding, which slightly increased surgical times, but did not require displacement of the implant site. Average surgical time was 62.08 min (range 50-75, standard deviation 9.40, median 62.5). At $\mathrm{T} 1$ in all cases we registered a grade 0 in Holgers classification (100\%). At T2, we registered only 1 case $(8.33 \%)$ of hyperaemia and swelling of the skin around the abutment, to which Holgers 1 was scored. All others classified as grade 0. At T3 in 2 cases (16.67\%), because of local inflammation, Holgers 2 was assigned; in 1 case $(8.33 \%)$ the patient showed significant signs of infection (Holgers 4) which required removal of the implant; in the remaining 9 cases $(75 \%)$ there was no local skin reaction (Holgers 0). At T4, of the 11 still implanted patients, another $(9.09 \%)$ presented significant signs of infection (Holgers 4) requiring the removal of the implant. All others classified as grade 0 . Thus, after 47 observations in total, we recorded the presence of postoperative complications in 5 cases $(10.63 \%)$.

\section{Group 2}

This technique was used in 8 cases (26.7\%). In this group, we never recorded intra-operative complications. Average surgical time was 34.37 min (range 25-40, standard 
Table II. Holgers classification of skin reaction in the three groups.

\begin{tabular}{|c|c|c|c|c|c|c|}
\hline & Holgers 0 & Holgers 1 & Holgers 2 & Holgers 3 & Holgers 4 & Mean score \\
\hline \multicolumn{7}{|l|}{$\mathrm{T} 1$} \\
\hline Group 1 & 12 & 0 & 0 & 0 & 0 & 0 \\
\hline Group 2 & 8 & 0 & 0 & 0 & 0 & 0 \\
\hline Group 3 & 9 & 0 & 1 & 0 & 0 & 0.2 \\
\hline \multicolumn{7}{|l|}{ T2 } \\
\hline Group 1 & 11 & 1 & 0 & 0 & 0 & 0.08 \\
\hline Group 2 & 8 & 0 & 0 & 0 & 0 & 0 \\
\hline Group 3 & 10 & 0 & 0 & 0 & 0 & 0 \\
\hline \multicolumn{7}{|l|}{$\mathrm{T} 3$} \\
\hline Group 1 & 9 & 0 & 2 & 0 & 1 & 0.41 \\
\hline Group 2 & 8 & 0 & 0 & 0 & 0 & 0 \\
\hline Group 3 & 10 & 0 & 0 & 0 & 0 & 0 \\
\hline \multicolumn{7}{|l|}{ T4 } \\
\hline Group 1 & 10 & 0 & 0 & 0 & 1 & 0.36 \\
\hline Group 2 & 7 & 1 & 0 & 0 & 0 & 0.12 \\
\hline Group 3 & 10 & 0 & 0 & 0 & 0 & 0 \\
\hline
\end{tabular}

T1: 7 days; T2: 30 days; T3: 60 days; T4: 1 year.

deviation 5.63, median 35). During the first three postoperative controls (T1, T2, T3), none of the patients (100\%) showed local skin reactions around the abutment (Holgers 0$)$. At T4, we registered 1 case (12.5\%) of hyperaemia and swelling of the skin around the abutment (Holgers 1), which was treated with local medications. Therefore, in a total of 32 observations, we reported postoperative complications in only 1 case $(3.12 \%)$.

\section{Group 3}

The new technique was used in 10 cases (33.3\%). During surgery, in one case $(10 \%)$ we recorded exposure of the Dura Mater after drilling at $3 \mathrm{~mm}$ with important bleeding as a complication; after stopping the bleeding, the abutment was directly applied without deepening the hole. The average surgical time was $18.7 \mathrm{~min}$ (range 9-40, standard deviation 9.59, median 17.5). On the first postoperative control (T1), 1 patient (10\%) showed signs of inflammation of the skin around the abutment (Holgers 2). The remaining 9 patients (90\%) did not show signs of skin inflammation (Holgers 0). In subsequent inspections (T2, T3, T4), we never observed local reactions (Holgers 0 , $100 \%$ of cases). In this group, out of a total of $40 \mathrm{ob}-$ servations we recorded only 1 postoperative complication $(2.5 \%)$.

\section{Discussion}

The advent of BAHIs has resulted in a considerable im- provement in overall quality compared to conventional bone conduction devices, as well as a significant reduction of tedious local and aesthetic complications related to the use of older devices. However, the application of bone-anchored implants can also be accompanied by complications, both intra-operative (bleeding, exposure of dura mater, cerebrospinal fluid leakage) and postoperative (necrosis of skin flaps, alopecia, local infections, implant extrusion, dysaesthesia, abnormal scarring with aesthetic consequences).

Since Tjellström's first description of the surgical technique, this has been modified in order to reduce the onset of these complications ${ }^{4}$. The original technique, which involved the creation of a skin flap with thinning of the subcutaneous tissue, was burdened with high rates of complications. The same Tjellström, in an initial review of the first 100 implants, reported implant extrusions in $10 \%$ of cases ${ }^{13}$. Reyes, instead, after 8 years of followup, recorded adverse implant skin reactions in $30 \%$ of cases ${ }^{14}$. In a large series of more than 1000 implants by modified technique (linear incision and thinning of the subcutaneous tissue), Dun reported adverse events during follow-up in $4.5 \%$ of cases ${ }^{15}$. Finally, in a series of 149 patients, House reported an incidence of local complications in $12.8 \%$ of cases (skin overgrowth, implant extrusion, wound infection, flap necrosis) ${ }^{16}$. In our experience, using this surgical technique (Group 1), we observed the development of complications in the postoperative period in $10.63 \%$ of cases. In particular, we recorded 2 cases of 
important infection at the implant site that required removal of the device at 60 days and 1 year after surgery, respectively.

The introduction of longer abutment has allowed a further evolution of the surgical technique, i.e. a linear incision without the need for thinning of the subcutaneous tissue. This has undoubtedly led to benefits in terms of local inflammatory reactions, time for wound healing and development of dysaesthesia, in addition to a better aesthetic result. Hultcrantz using this technique reported local infection in $14 \%$ of cases, compared to $43 \%$ of surgeries with thinning of the subcutaneous tissue ${ }^{9}$. In a recent paper, Den Besten, using the tissue preservation technique, scored a higher percentage of local reactions (28\%) compared to a control group subjected to linear incision with thinning of the subcutaneous tissue (4\%); these local reactions were managed with 1-2 local medications ${ }^{17}$. Even Martinez et al. compared these two techniques, observing a significant reduction of local reactions of a certain entity (Holgers 3 ) after 1 week after surgery in the case of the subcutaneous tissue preservation (preservation $7 \%$ vs thinning 28\%); however, the authors reported a higher percentage of minor local reactions (Holgers 1-2: $93 \%$ vs $72 \%$ ), but a faster healing rate at 1 month after surgery (Holgers 0-1: 86\% vs 75\%) ${ }^{18}$. In a recent paper, Caruso et al., using the linear cut without thinning of the subcutaneous tissue on 49 patients, observed mild skin reactions (Holgers 0 or 1$)$ in $96 \%$ of the visits $(n=116)$; the authors reported five adverse skin reactions (Holgers $\geq 2$ ) across all visits $(4 \%)^{19}$. During follow-up of the tissue preservation technique, in our series (Group 2) we observed local reactions in $3.12 \%$ of cases, thereby confirming a significant reduction in surgical trauma that is typically found in patients who underwent the technique with thinning of the subcutaneous tissue.

Finally, the latest evolution of the technique has permitted to further limit trauma, reducing duration of surgery at the same time. The use of a biopsy punch, and the drilling and placement of the implant through the incision allows for less manipulation of surrounding tissues, therefore reducing the risk of complications. The disadvantages of this technique consist in the lower visibility of the surgical area, which is in part obviated by using the operating microscope. Goldman in 2013 described the use of this technique on 15 patients, employing a $12 \mathrm{~mm}$ diameter biopsy punch; in the postoperative period, the author observed mild hyperaemia of the surgical area in all cases, but no complications of Holgers 2 or higher ${ }^{10}$. Later, Wilson et al. used a $4 \mathrm{~mm}$ diameter biopsy punch with enlargement of the surgical area, removing the surrounding subcutaneous tissue and periosteum in a conical shape from the scalp to the cranial surface, to improve the visualisation of the site of implant; out of 11 patients, the authors reported 2 cases of local reaction with Holgers 2 or higher in the postoperative follow-up that were treated with local medications ${ }^{20}$. In 2015, Gordon and Coelho compared the punch technique with the linear incision plus thinning technique; they used a 6-mm diameter biopsy punch, removing skin, subcutaneous tissue and periosteum in a single step. Two cases of local reaction (Holgers $\geq 2$ ) were observed at the first and at the last postoperative control and 1 case of implant extrusion (despite a Holgers 0 during the first control) ${ }^{3}$. The latest evolution of the punch technique was introduced by Oticon Medical AB (Askim, Sweden) and called "MIPS"; the aim was to optimise preservation of tissues, minimise trauma and provide a standardised procedure and surgical instruments, thus eliminating surgical variability.

Using this surgical technique (Group 3), we recorded only 1 case $(10 \%)$ of inflammatory reaction around the abutment during the first postoperative control, that was easily treated with local medication; at subsequent controls, we did not observe local reactions (postoperative complication rate, $2.5 \%$ ).

When comparing the local reactions in the 3 groups, we did not record significant differences during follow-up $(\mathrm{T} 1, \mathrm{p}=0.38 ; \mathrm{T} 2, \mathrm{p}=0.48 ; \mathrm{T} 3, \mathrm{p}=0.11 ; \mathrm{T} 4, \mathrm{p}=0.55$, one-way ANOVA test); therefore, in our experience, the use of less invasive surgical techniques does not affect the rate of postoperative complications, which is already low compared to previous techniques.

In our opinion, a very interesting aspect of this study consists in the significant reduction of surgical time that shows a decreasing tendency from the linear incision technique with thinning of the subcutaneous tissue, to the linear incision technique and preservation of the subcutaneous tissue, to the MIPS technique. In Group 1, in fact, the average intervention duration was $62.08 \mathrm{~min}$ (range 50-75, standard deviation 9.40, median 62.5) vs 34.37 min (range 25-40, standard deviation 5.63, median 35) in Group 2 and 18.7 min (range 9-40, standard deviation 9.59, median 17.5) in Group 3, with statistically significant differences $(\mathrm{p}<0.00001$, one-way ANOVA test). In the 2011 Hultcrantz study, the average duration of interventions with and without subcutaneous tissue thinning (linear incision for both groups) was, respectively, 44.6 and $28.1 \mathrm{~min}^{9}$; using the same techniques, Martinez in 2015 reported similar durations (42 and $27 \mathrm{~min}$, respectively), while Den Besten recorded shorter surgeries (31.9 and $24.6 \mathrm{~min}$, respectively) ${ }^{17}{ }^{18}$. Caruso et al., using the technique with linear incision and preservation of the subcutaneous tissue, showed a mean surgical time 
of $20.3 \mathrm{~min}{ }^{19}$. Using the punch techniques, Goldman reported a mean duration of the surgery of $15.2 \mathrm{~min}$, against 32.3 min reported by Wilson and the 13.4 min reported by Gordon and Coelho ${ }^{31020}$. The MIPS technique, at the current time, has only been described in the recent multicentre study by Johansson et al., which reported an average duration of the surgery of $16 \mathrm{~min}^{21}$.

It is therefore evident how the shift to less invasive techniques involves a significant reduction in surgical time; in our experience, we recorded slightly longer times in the use of the two techniques with linear incision compared to the literature, while using the MIPS technique we observed a similar duration to that of other experiences with punch and to the only existing study with MIPS. In our opinion, the reduction of surgical time that we observed in our series in the transition from the more invasive to less invasive techniques should not be attributed to a learning curve, since all surgeries (except for 2 MIPS) were performed by the same experienced surgeon (PV). Moreover, we noticed that both 2 interventions with MIPS technique performed by the young surgeon (RP) had a duration of $20 \mathrm{~min}$, which is very close to the average value of the other 8 procedures performed with the same technique by the experienced surgeon (18.37 $\mathrm{min})$, with no statistically significant difference $(\mathrm{p}=0.84$, unpaired t-test); therefore, we believe that the shorter duration of the operations carried out with MIPS technique is related to the surgical technique and not the surgeon's experience. It is also important to note that in the same group (Group 3) we registered a case of lengthening of surgical time (40 $\mathrm{min}$ ) because of an intra-operative complication (dura mater exposure with important bleeding).

The present study, being a retrospective study, lacks statistical power. The case study, nevertheless, is definitely limited by the low number of patients eligible for this kind of prosthetic application or who accept this solution. Another limit is represented by the short duration of followup, given that local complications, especially of aesthetic nature, may also appear at a later time. In this regard, it is important to not underestimate possible variability among the patients in daily care for the appropriate cleaning of skin-abutment interface; indeed, poor hygiene of the implant site can determine the appearance of late complications. However, we think that this risk was the same for all three study groups, because is independent of the surgery technique, and so it does not represent a possible bias. Adequate counseling with regards to the absolute need of a daily cleaning of the skin-abutment interface was similarly given to all patients in the three groups. Moreover, the importance of a correct hygiene was stressed during each control visit in the outpatient clinic. Finally, a fur- ther limitation could be not having performed a blinded follow-up. We believe, however, that comparing three different surgical techniques for the application of BAHIs allows us to obtain interesting data about the benefits of the new MIPS technique, especially in relation to the duration of the intervention and its simplicity of execution.

In the present study, we did not consider the time required for osseointegration and stability of the system, in addition to various audiological parameters. In this regard, there is an ongoing randomised controlled trial by Calon et al. to compare the MIPS and linear incision techniques with preservation of subcutaneous tissue, by assessing various parameters that may help in the prediction of outcomes and complications ${ }^{22}$. The study is still ongoing and the authors expect to complete it in August 2018.

\section{Conclusions}

The surgical techniques for the application of percutaneous bone-anchored implants have been refined over the years, with the aim of reducing the healing time, local complications and aesthetic consequences. This study confirms the low rate of intra- and postoperative complications of the described techniques and attests the simplicity of execution of the MIPS technique, with a significant reduction of surgical time compared to the other two techniques, and positive effects in terms of health care costs.

To the best of our knowledge, this is the first study that compares the MIPS technique to linear incision techniques, with or without preservation of subcutaneous tissue.

\section{References}

1 Holgers KM, Tjellström A, Bjursten LM, et al. Soft tissue reactions around percutaneous implants: a clinical study of soft tissue conditions around skin-penetrating titanium implants for bone-anchored hearing aids. Am J Otol 1988;9:56-9.

2 Audia Akustik GMBH. Innovative hearing systems. Herrenstraße 6, 30159 Bruckhoff Hannover, Germany. www.bruckhoff.com.

3 Gordon SA, Coelho DH. Minimally invasive surgery for osseointegrated auditory implants: a comparison of linear versus punch techniques. Otolaryngol Head Neck Surg 2015;152:1089-93.

4 Tjellström A, Lindström J, Hallén O, et al. Osseointegrated titanium implants in the temporal bone. A clinical study on bone-anchored hearing aids. Am J Otol 1981;2:304-10.

5 Altuna X, Navarro JJ, Palicio I, et al. Bone-anchored hearing device surgery: Linear incision without soft tissue reduction. A prospective study. Acta Otorhinolaryngol Esp 2015;66:258-63.

6 de Wolf MJ, Hol MK, Huygen PL, et al. Clinical outcome 
of the simplified surgical technique for BAHA implantation. Otol Neurotol 2008;29:1100-8.

7 Bovo R. Simplified technique without skin flap for the boneanchored hearing aid (BAHA) implant. Acta Otorhinolaryngol Ital 2008;28:252-5.

8 Husseman J, Szudek J, Monksfield P, et al. Simplified boneanchored hearing aid insertion using a linear incision without soft tissue reduction. J Laryngol Otol 2013;127(Suppl 2):S33-8.

9 Hultcrantz M. Outcome of the bone-anchored hearing aid procedure without skin thinning: a prospective clinical trial. Otol Neurotol 2011;32:1134-9.

10 Goldman RA, Georgolios A, Shaia WT. The punch method for bone-anchored hearing aid placement. Otolaryngol Head Neck Surg 2013;148:878-80.

11 Clamp PJ, Briggs RJ. The cochlear baha 4 attract system, design concepts, surgical technique and early clinical results. Expert Rev Med Devices 2015;12:223-30.

12 Briggs R, Van Hasselt A, Luntz M, et al. Clinical performance of a new magnetic bone conduction hearing implant system: results from a prospective, multicenter, clinical investigation. Otol Neurotol 2015;36:834-41.

13 Tjellström A, Granström G. Long-term follow-up with the bone-anchored hearing aid: a review of the first 100 patients between 1977 and 1985. Ear Nose Throat J 1994;73:112-4.

14 Reyes RA, Tjellstrom A, Granstrom G. Evaluation of implant losses and skin reactions around extraoral bone-anchored implants: a 0- to 8-year follow-up. Otolaryngol Head Neck Surg 2000;122:272-6.

15 Dun CA, Faber HT, de Wolf MJ et al. Assessment of more than 1,000 implanted percutaneous bone conduction de- vices: skin reactions and implant survival. Otol Neurotol 2012;33:192-8.

16 House JW, Kutz JW Jr. Bone-anchored hearing aids: incidence and management of postoperative complications. Otol Neurotol 2007;28:213-7.

17 den Besten CA, Bosman AJ, Nelissen RC, et al. Controlled clinical trial on bone-anchored hearing implants and a surgical technique with soft-tissue preservation. Otol Neurotol 2016;37:504-12.

18 Martínez P, López F, Gómez JR. Cutaneous complications in osseointegrated implants: comparison between classic and tissue preservation techniques. Acta Otorhinolaryngol Esp 2015;66:148-53.

19 Caruso A, Giannuzzi AL, Sozzi V, et al. Bone anchored hearing implants without skin thinning: the Gruppo Otologico surgical and audiological experience. Eur Arch Otorhinolaryngol 2017;274:695-700.

20 Wilson DF, Kim HH. A minimally invasive technique for the implantation of bone-anchored hearing devices. Otolaryngol Head Neck Surg 2013;149:473-7.

21 Johansson ML, Stokroos RJ, Banga R, et al. Short-term results from seventy-six patients receiving a bone-anchored hearing implant installed with a novel minimally invasive surgery technique. Clin Otolaryngol 2017;42:1043-8.

22 Calon TG, van Hoof M, van der Berge H, et al. Minimally Invasive Ponto Surgery compared to the linear incision technique without soft tissue reduction for bone conduction hearing implants: study protocol for a randomized controlled trial. Trials 2016;17:540. 